\title{
Evolution of individual equatorial atmospheric Kelvin waves in the stratosphere from FORMOSAT-7/COSMIC-2 temperatures
}

Uma Das ${ }^{1^{*}} \mathbb{D}$, Chen-Jeih Pan $^{2}$ and Shih-Sian Yang ${ }^{2}$

\begin{abstract}
Temperatures obtained from Formosa Satellite-7/Constellation Observing System for Meteorology, lonosphere and Climate-2 (FORMOSAT-7/COSMIC-2) in the stratosphere are analysed to investigate equatorial atmospheric Kelvin waves (KW) during the period from October 2019 to March 2021. Least square fitting followed by a two-dimensional fast Fourier transform are employed to extract the characteristics of these waves. Comparison with ERA5 mean zonal winds clearly indicates wave-mean flow interactions. KW activity was stronger from November 2019 to July 2020 and observed in the entire stratosphere due to the prevailing westward wind. After July 2020, although the ambient winds were favourable, wave activity was weaker and is attributed to the La Nina state of El Nino Southern Oscillation (ENSO) in the equatorial Pacific. The emphasis of the current study is on individual KW events and their evolution as they propagate eastward and upward. Waves of many periods are excited simultaneously in the lower atmosphere and as they propagate upward with different speeds, disperse along the path. During November-December 2019, KW periods ranged from 8 to 21 days. Vertical wavelength of the slow waves (>15 days) is found to be $\sim 3 \mathrm{~km}$ just above the tropopause that increased to $10-12 \mathrm{~km}$ at $\sim 40 \mathrm{~km}$. This increase in vertical wavelength is due to Doppler effect of the mean wind on the wave. For the fast waves of periods $8,6.5$ and 4.5 days, the wavelengths are larger and 18, 24 and $30 \mathrm{~km}$, respectively. COSMIC-2 data, with its high vertical resolution, provided this opportunity to investigate the fine structure of the KW delivering many insights into the atmospheric dynamics involved.
\end{abstract}

\section{Key Points}

1. Kelvin waves of different periods are excited simultaneously that later disperse.

2. Vertical wavelength of slow Kelvin waves changes with altitude due to mean wind.

3. La Nina suppresses Kelvin wave activity in the equatorial middle atmosphere.

Keywords: Kelvin waves, GPS RO, Stratospheric dynamics, Doppler effect

\footnotetext{
*Correspondence: uma@iiitkalyani.ac.in

${ }^{1}$ Indian Institute of Information Technology Kalyani, Kalyani 741235, West

Bengal, India

Full list of author information is available at the end of the article
}

\section{Introduction}

Kelvin waves $(\mathrm{KW})$ are eastward propagating planetary waves (PW) generated in the equatorial lower atmosphere. They are forced by the Sun mainly through evaporation and subsequent latent heat release in convective clouds near the tropopause region. KW are confined to equatorial and low latitudes by the Coriolis force and a distinctive feature of these waves is that they are 
symmetric about the equator in zonal wind and temperature and virtually absent in the meridional winds. $\mathrm{KW}$ are slow in the lower stratosphere (periods $\sim 10-20$ days), fast in the upper stratosphere (periods 5-10 days) and ultra-fast in the mesosphere and lower thermosphere (MLT, periods $\sim$ 3-4 days). Ultra-fast Kelvin waves (UFKW) are also found in the ionosphere and thermosphere (IT) system (Takahashi et al. 2007). The vertical wavelength of these waves increases with decreasing period, thereby decreasing their susceptibility to dissipation as they propagate upward (Forbes et al. 2009). Slow $\mathrm{KW}$ contribute to the equatorial quasi-biennial oscillation (QBO) by transporting eastward momentum from lower atmosphere to stratospheric altitudes and driving the descent of the westerly (eastward wind) regimes of the QBO (Lindzen and Holton 1968; Baldwin et al. 2001).

KW in the atmosphere were first suggested by Matsuno (1966), and Holton and Lindzen (1968) discussed them specifically as a special solution to linearised equations for an equatorial $\beta$-plane. Later, Wallace and Kousky (1968) showed observational evidence for KW in the tropical stratospheric zonal winds and temperature using radiosonde data. Subsequent studies focused on the identification of these waves in many groundbased (Kumar et al. 2019) and satellite-based observations (Hirota 1979; Salby et al. 1984; Canziani et al. 1994; Mote et al. 2002), radiosonde data (Holton et al. 2001) and models (Lott et al. 2014; Chen and Miyahara 2012). The climatology of slow and fast $\mathrm{KW}$ and their effects on the equatorial stratospheric QBO is currently well established (Canziani and Holton 1998; Canziani et al. 1994; Ern and Preusse 2009a, b; Das and Pan 2013, 2016; Pan et al 2020). Contribution of KW to QBO wind reversal is $30-50 \%$ and $20-35 \%$ to total forcing in the stratosphere (Ern and Preusse 2009a, b). Studies of UFKW described their general characteristics (see Davis et al. (2012) and references therein) and showed that UFKW can travel to thermospheric heights and also drive changes further up (Forbes 2000; Takahashi et al. 2007; Forbes et al. 2009; Chang et al. 2010; Chen et al. 2018); however, their effects on the IT region are yet to be examined in detail. Modelling studies are indicating significant effects of UFKW on MLT and IT region including day-to-day variability (Triplett et al. 2019; Yamazaki et al. 2020).

A 7-day KW was investigated using radiosonde measurements of temperature and winds over different sites in South east Asia during a one-month period of 10 April-9 May, 2004 (Sridharan et al. 2006). Due to the limitation of altitude coverage, the studies were confined to the lower stratosphere only. It was established that a strong event of convection was responsible for these waves during this period. Using lidar observations, planetary wave climatology in the middle atmosphere was derived from Indian low latitudes (Kumar et al. 2019). Their results indicated the presence of vertical propagating quasi 12-day and quasi 16-day waves and emphasised the importance of these waves on the QBO.

Many studies also investigated temperatures from Sounding of the Atmosphere using Broadband Emission Radiometry (SABER) instrument on board the Thermosphere Ionosphere Mesosphere Energetics Dynamics (TIMED) satellite. Forbes et al (2009) investigated KW from the stratosphere to the lower thermosphere using SABER data during 2002 to 2006 and found waves of wavenumber 1 of 5-10 days in the stratosphere having vertical wavelengths from 9 to $13 \mathrm{~km}$. The dominant waves higher up in the MLT region were UFKW that had 2-3 days periods and $35-45 \mathrm{~km}$ vertical wavelengths. These vertical wavelengths were calculated using the following dispersion relation.

$$
L_{z}=\frac{2 \pi}{N}\left[\frac{L_{x}}{\tau}-\bar{u}\right]
$$

where $L_{x}$ and $L_{z}$ are the horizontal and vertical wavelengths, $\tau$ is the period, $\bar{u}$ is mean wind, $N$ is buoyancy frequency (Holton et al. 2001). UFKW were also investigated using Aura Microwave Limb Sounder (MLS) satellite data along with meteor radar data during the period from 2005 to 2010 (Davis et al. 2012). Many high amplitude UFKW events were identified in the MLT region and vertical wavelengths calculated from phase information of the observed waves has a mean of $44 \pm 2 \mathrm{~km}$. This number matched very well with the theoretically computed vertical wavelengths computed using Eq. (1). They concluded that UFKW play a crucial role in carrying intra-seasonal oscillations to the MLT region, although no strong correlation was found between any of the sources from lower atmosphere to the independent UFKW events.

Chen et al (2018) also analysed SABER data from 2003 to 2016 using two-dimensional fast Fourier transform (2D-FFT) for investigating properties of UFKWs above $40 \mathrm{~km}$. After comparisons with background winds in MLT region from the horizontal wind model 2014 (HWM14) (Drob et al. 2015) and in the upper stratosphere from European Centre for Medium-Range Weather Forecasts (ECMWF) interim reanalysis (Dee et al. 2011), it was found that large amplitude UFKWs occurred during westward phases of mesospheric and stratospheric semi-annual oscillations, indicating filtering by the mean winds. A correlation study was conducted and time lags between the $90-\mathrm{km}$ wave variation and lower altitude wave variations did not match the theoretical expectation of the upward wave group velocity. 
With the advent of Global Positioning System based Radio Occultation (GPS RO) measurements of the atmosphere, properties of Kelvin waves could be investigated in detail (Tsai et al. 2004; Randel and Wu 2005; Tsuda et al. 2006; Ratnam et al. 2006; Pan et al. 2011; Scherllin-Pirscher et al. 2017). KW were studied by Randel and Wu (2005) in GPS RO derived temperatures from Challenging Minisatellite Payload (CHAMP) and (SAC-C) during 2001-2002. KW with periods of 20 days and vertical wavelengths of $4-8 \mathrm{~km}$ were found with coherent vertical structure in the upper troposphere and lower stratosphere. Enhanced amplitudes coincided with descending westerlies and correlated well with outgoing longwave radiation (OLR) and thereby with transient deep convections over Indonesia. Ratnam et al (2006) extended the study with CHAMP data and investigated the KW during 2001-2005 in the stratosphere and the study revealed the wave-mean flow interactions and established the importance and use of GPS RO data in these studies. A strong correlation of KW was also observed with the tropopause height and temperature. The climatological features showed an annual variation with Northern Hemisphere winter maximum and summer minimum. The climatology also correlated well with the tropopause height and temperature. These results were based on 3 adjacent days' data and KW with periods greater than 10 days only were studied. The FORMOSAT-3/COSMIC mission provided a huge leap in amount of data available for these studies and KW were investigated in greater detail (Pan et al. 2011; Scherllin-Pirscher et al. 2017; Ho et al. 2020). $\mathrm{KW}$, being sub seasonal in nature, are highly intermittent but still explain about half of the sub-seasonal variance at the equatorial tropopause region and are significantly modulated by QBO above $20 \mathrm{~km}$ (Scherllin-Pirscher et al. 2017). Several peaks of KW variance coincided with those in convective forcing where OLR was used as a proxy, and yet many other episodes remained unrelated. Das and Pan (2013) investigated a specific KW event during November 2008 in the stratosphere that had a large vertical wavelength and hence did not interact with the mean flow and propagated vertically up creating a minor change in mean wind direction of the QBO, thereby affecting its fine structure. A more interesting study by Das et al. (2016) identified effects of El Nino on QBO where $\mathrm{KW}$ played a major role in producing a fast-descending westerly during 2010. Although El Nino events are capable of increasing the KW activity, their upward propagation purely depends on the state of the mean winds.

Most of these studies focused on the long term climatological and morphological features in the stratosphere and MLT regions. The sources of individual KW events and their evolution as they propagate upward is still an open question in understanding their generation mechanisms and effects on the equatorial atmospheric dynamics. In the current study an attempt is made to investigate the features of individual KW events in the stratosphere using the latest data of COSMIC-2. Data used and methodology are explained in Sect. 2 and results are discussed in Sect. 3. A summary and concluding remarks are provided in Sect. 4.

\section{Data and methodology}

\subsection{Temperatures from COSMIC-2 and data analysis}

FORMOSAT-7/COSMIC-2 is the second set of a constellation of micro-satellites launched by Taiwan and United States to study the atmosphere based on GPS RO technique (Schreiner et al. 2020). COSMIC-2 measurements cover the latitudinal region between $40^{\circ} \mathrm{S}$ and $40^{\circ} \mathrm{N}$ due to a low GPS inclination of $24^{\circ}$. Globally $4000-5000$ profiles are being generated everyday. Data is available in 'nearreal time' from surface to $60 \mathrm{~km}$ with $0.1 \mathrm{~km}$ resolution and initial validation studies of bending angle and refractivity with other datasets indicate good performance upto $40-45 \mathrm{~km}$ (Schreiner et al. 2020). 'WetPf2' temperature data for the period from September 2019 to March 2021 (UCAR COSMIC Program 2019) is analysed in the current study for investigating atmospheric $\mathrm{KW}$ over the equatorial region in the latitudinal band of $\pm 5^{\circ}$. Neglecting the time of observation, least squares fit for planetary waves is performed with dominant wavenumbers from 1 to 6 (PW1 to PW6) for all observations on a given day as follows.

$$
T(\lambda)_{h d}=\bar{T}_{h d}+\sum_{s=1}^{6} A_{h d}^{s} * \cos \left(2 \pi s \lambda-\phi_{h d}^{s}\right)
$$

$T(\lambda)_{h d}$ is the temperature as a function of longitude $\lambda$ in the equatorial region $\left( \pm 5^{\circ}\right)$ at altitude $h$ and on day number $d, \bar{T}_{h d}$ is the zonal mean temperature, $A_{h d}^{s}$ and $\phi_{h d}^{s}$ are amplitudes and phases of planetary waves of wavenumbers $s$ (ranging from 1 to 6 , hereinafter referred to as PW1 to PW6). During the study period, the COSMIC satellites were yet to be deployed into designated evenly spaced circular orbits at $550 \mathrm{~km}$. However, the sampling pattern in the longitude-universal time space was uniform as point of measurement depends on both the low Earth orbit COSMIC2 satellite and the high-altitude GPS satellite. Thereby, neglecting the time of observations does not result in any aliasing from tidal components. The amplitudes and phases of the PW are investigated as a function of day number and altitude to understand the evolution of the various wave events. Phase plots are specifically analysed to obtain the vertical wavelength of the different waves. A 2D-FFT is also used on reconstructed temperature variability obtained from the least squares 
fits in Eq. (2) to identify the dominant waves and their periods in the spectral domain.

\subsection{Zonal winds from ERA5}

ERA5 is the fifth generation reanalysis of European Centre for Medium-Range Weather Forecasts (ECMWF) that provides hourly data of various atmospheric parameters on pressure levels from 1000 to $1 \mathrm{hPa}$ from 1979 to present (Hersbach et al. 2018). Reanalysis combines model data with global observations, including satellite observations, to obtain a global dataset representing the amtosphere. Since 2006, GPS RO data from COSMIC missions are also being assimialted into the ERA datasets to reduce temperature biases (Poli et al. 2010; Dee et al. 2011).

In the current study, u-component of wind (zonal wind) over the equatorial latitudes in the range of $\pm 5^{\circ}$ is obtained from ERA5 and averaged over all longitudes to get the daily zonal mean zonal wind [Copernicus Climate Change Service (C3S) 2017]. It is investigated in conjunction with the amplitudes of the PW obtained from COSMIC-2 temperature least square fitting analysis to investigate the wave-mean flow interactions in the stratosphere.

\section{Results and discussion}

Temperature variability is reconstructed using amplitudes and phases of each PW obtained from least squares fitting given in Eq. (2). These wave variabilities at a specific altitude, called the Hovmöller diagrams (Hovmöller 1949), are plotted in Fig. 1 for wavenumbers 1-6 (PW1 to PW6) as a function of longitude and time during a two-month period from November to December 2019. PW1 are visibly eastward and can be recognised as KWs. The amplitudes are varying between $\pm 4 \mathrm{~K}$ and are particularly large, reaching $\pm 5 \mathrm{~K}$, on 1st December 2019. The waves of higher wavenumbers from 2 to 6 are mostly stationary and eastward propagation is observed occasionally in PW2 and PW3. Also, the amplitudes of the waves are reducing with increasing wavenumber. PW2 amplitudes are confined to $\pm 3 \mathrm{~K}$ and maximum amplitudes are observed during mid-November, when PW1 activity was lower. Conversely, a few days around 1st December 2019, when maximum PW1 amplitudes are observed, PW2 is almost negligible. This figure indicates that PW1 have the greatest impact on the stratospheric dynamics. Although the waves, particularly PW1, are identified as KW, they are continued to be called planetary waves as there is contribution from stationary and westward propagating waves.

\subsection{Long term variations in the wave activity}

Amplitudes of PW1 and PW2 in the equatorial stratosphere within $\pm 5^{\circ}$ latitudes are shown in Fig. 2a, b during the period from September 2019 to March 2021. Waves of higher wavenumbers $(>2)$ are not discussed further due to their smaller amplitudes, as seen earlier. Daily zonal mean zonal wind from ERA5 reanalysis is shown in Fig. 2(c) and the zero wind contours are overplotted in Fig. 2a, b to understand the wave-mean flow interactions in the equatorial stratosphere. Figure $2 \mathrm{~d}$ shows mean OLR within $\pm 5^{\circ}$ latitudes from NOAA (Liebmann and Smith 1996) highlighting the regions of strong convection indicated by low OLR $\left(<210 \mathrm{~W} / \mathrm{m}^{2}\right)$

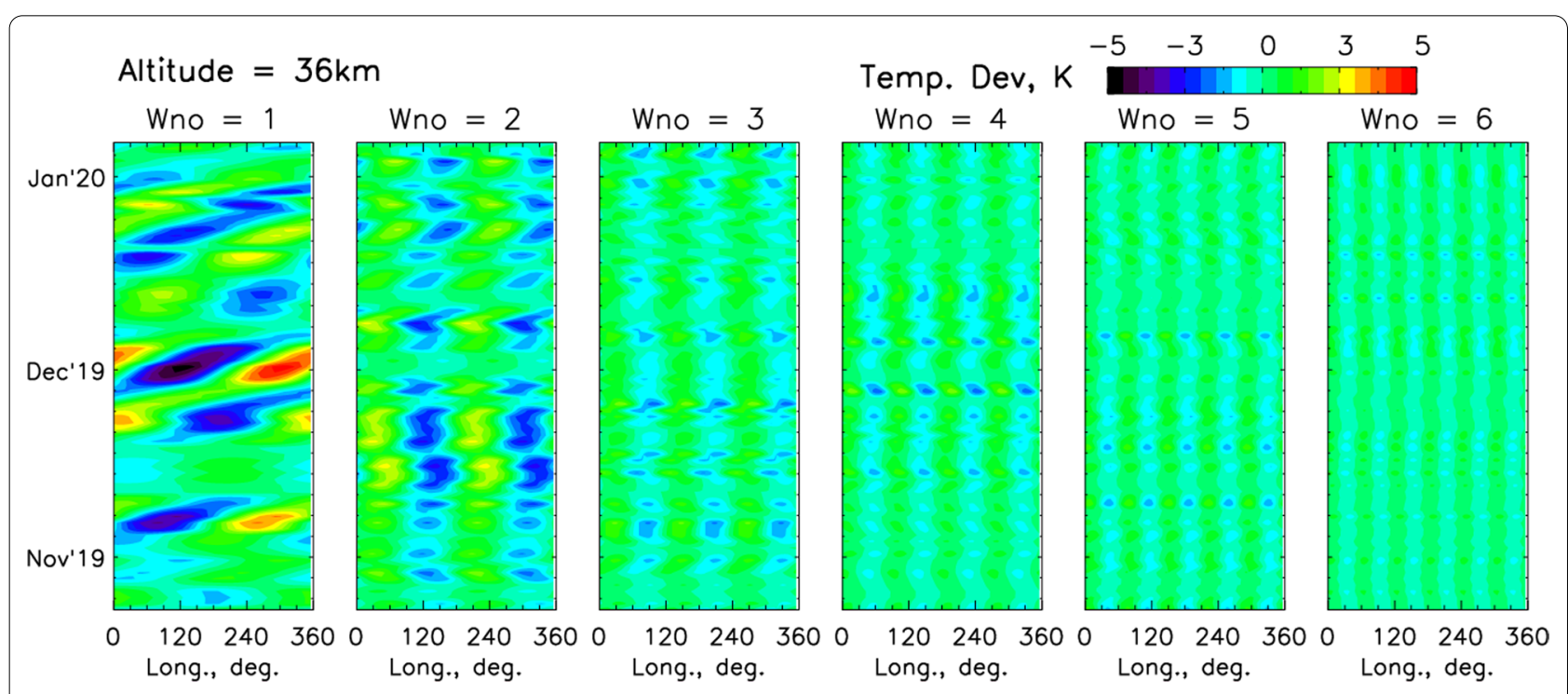

Fig. 1 Hovmöller diagrams of PW1 to PW6 in the equatorial stratosphere within $\pm 5^{\circ}$ latitudes at $36 \mathrm{~km}$ 


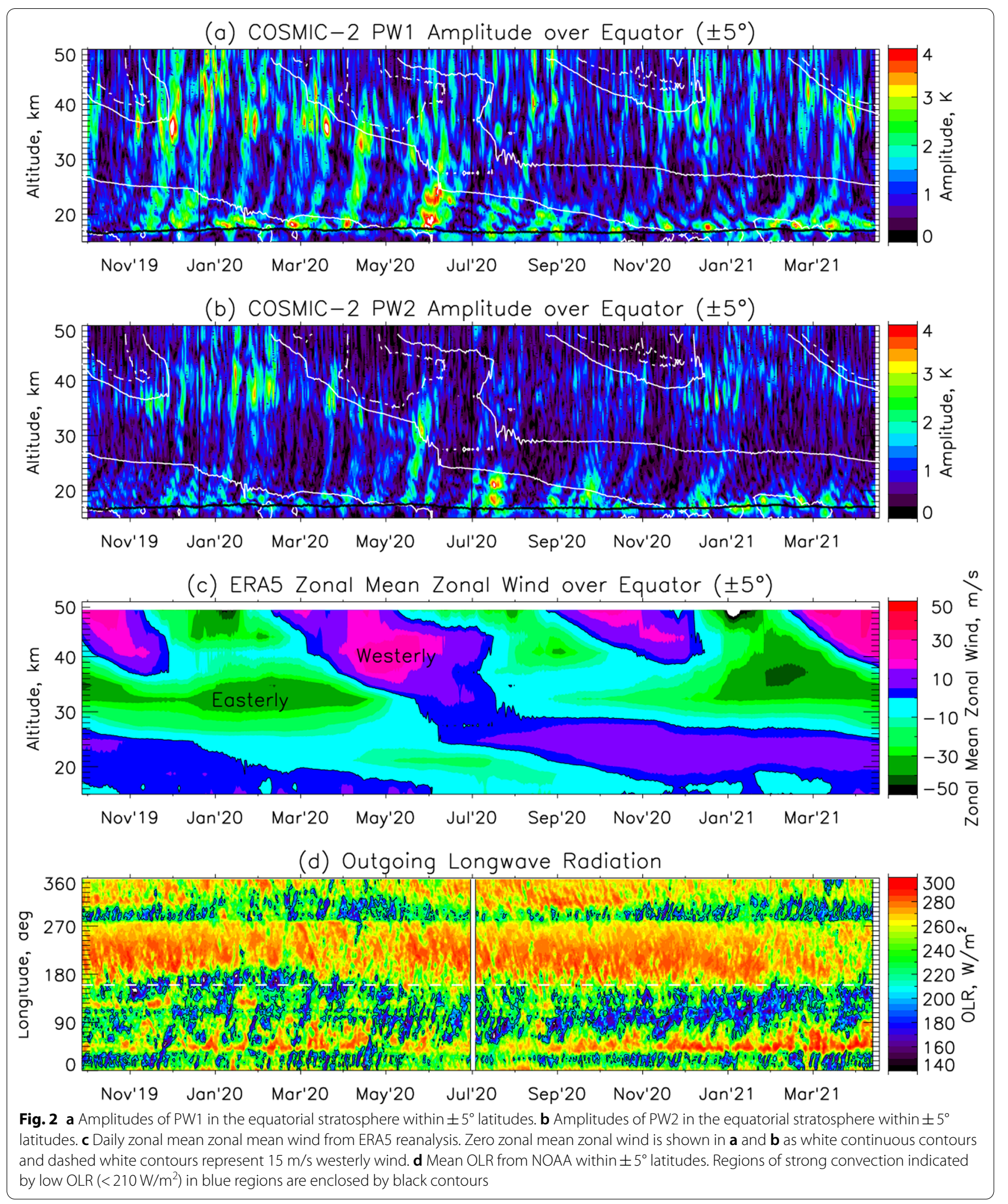


in blue regions enclosed by black contours. In the zonal mean zonal wind, stratospheric semi-annual oscillation (SSAO) is observed at $40 \mathrm{~km}$ during October/November and April/May along with the QBO, where a westerly during April/May 2020 at $40 \mathrm{~km}$ rapidly descended to $25 \mathrm{~km}$ in July 2020 . This westerly regime is maintained at $25 \mathrm{~km}$ and extends up to April 2021. The observed waves in Fig. 2a, b occur intermittently near the tropopause with no specific pattern and have significant amplitudes greater than $2 \mathrm{~K}$ and occasionally reaching $4-5 \mathrm{~K}$. These waves propagate upward through the easterly (westward wind) regime of the QBO; as they encounter the zero-wind line of the descending westerly from November 2019 to June 2020 their amplitudes suddenly reduce. At $\sim 36 \mathrm{~km}$ the amplitudes of PW1 reach $5 \mathrm{~K}$ and those of PW2 reach $3.5 \mathrm{~K}$. Such activity, with comparatively smaller amplitudes, is observed once again during December 2020 to March 2021 and is expected to continue. During July-August 2020, PW1 of 2-3 K are observed below $25 \mathrm{~km}$, and some of these waves are capable of crossing the westerly regime. PW2 amplitudes are much higher reaching $5 \mathrm{~K}$ during July but are confined to altitudes less than $25 \mathrm{~km}$, beyond which the mean zonal wind is westerly. Large amplitudes of $3 \mathrm{~K}$ are also observed during September 2020 and November 2020 for PW2. These wave-mean flow interactions with the zonal mean zonal wind indicate that the observed planetary scale waves in Fig. 2a, b are predominantly eastward propagating and are KW. It has been established in many earlier studies based on observations that KW transport energy and momentum from the lower atmosphere to the stratosphere and contribute to the descent of westerly regimes of the QBO (e.g., Ratnam et al. 2006; Ern and Preusse 2009a, b; Pan et al. 2011). The climatology and morphology of KW are also well discussed in literature (e.g., Forbes et al. 2009; Davis et al 2012; Pan et al. 2020) and the general observations here are in perfect agreement with earlier studies and understanding.

The amplitudes of PW1 and PW2 are larger from November 2019 to June 2020, i.e., during the first half of the study period, and observed in the entire stratosphere due to the prevailing westward wind. During the second half, although the ambient winds were favourable, the amplitudes of both PW1 and PW2 are comparatively smaller. At the tropopause region also, amplitudes of PW1 are stronger during the first half of the study period and moderately weaker in the second half. On the other hand, amplitudes of PW2 are comparatively larger during the second half at the tropopause region. Similar high amplitudes of KWs were observed in 2009/2010 under El Nino conditions that had a huge impact on the QBO by inducing a fast-descending westerly (Das and Pan 2013). It was envisaged that processes contributing to El Nino also could have contributed to the increased KW activity via westerly wind events. In the current study, El Nino Southern Oscillation (ENSO) was in a neutral state until mid-2020 and beyond that a La Nina event occurred (Voosen 2021). The weaker wave activity observed in the second half could be due to the negative ENSO cycle. El Nino has a positive impact on KW activity by amplifying the eastward movement of the convective disturbances into the Pacific Ocean and the reverse happens during La Nina where these eastward movements are suppressed (Yang and Hoskins 2013; Domeisen et al 2019). This is further clarified by investigating the outgoing long wave radiation (OLR) shown in Fig. 2d. Up to mid2020, eastward propagating low OLR bands, indicative of the sources for strong KW activity, are observed to be moving well into the central Pacific region, up to $190^{\circ}$ longitude, indicating enhancement of the KW activity generation. A white dashed line is drawn at $160^{\circ}$ longitude to aid the eye. During the second half of the study period, such intrusions are not observed and convective regions are confined to the Indonesian and East Pacific regions only. This is clear indication of the La Nina event's negative impact on the KW activity.

These morphological features and long-term variabilities of the KW activity have been investigated extensively in literature via various ground- and satellite-based observations as well as modelling studies as discussed earlier. Observations from COSMIC-2 are thereby proving very precious in continuing these studies and combination of all GPS RO measurements till date will provide useful insights into understanding the long-term KW activity and its effect on stratospheric dynamics. The focus of the current study is the evolution of the individual KW from the tropopause, where they are generated, to the upper stratosphere and are discussed in the next subsection.

\subsection{Evolution of individual Kelvin waves}

Figure 3 shows the amplitudes and phases of PW1 and PW2 over the equatorial atmosphere within $\pm 5^{\circ}$ latitudes during the two-month period of November to December 2019. Amplitudes less than $1 \mathrm{~K}(0.5 \mathrm{~K})$ and the corresponding phases are not shown for PW1 (PW2) in the figure for clarity. Zero-wind contours of zonal mean zonal wind from ERA5 are also overplotted. Up to 28th November, the waves are blocked by the zero wind contours of the descending westerly of the SSAO at 36-37 km; beyond this time, the waves travel to higher altitudes unimpeded as they encounter westward winds. This is the reason for choosing this period for detailed investigations, as the observed waves propagate from tropopause to upper stratosphere. PW1 with large amplitudes start on 13th November at $17 \mathrm{~km}$ and with time 


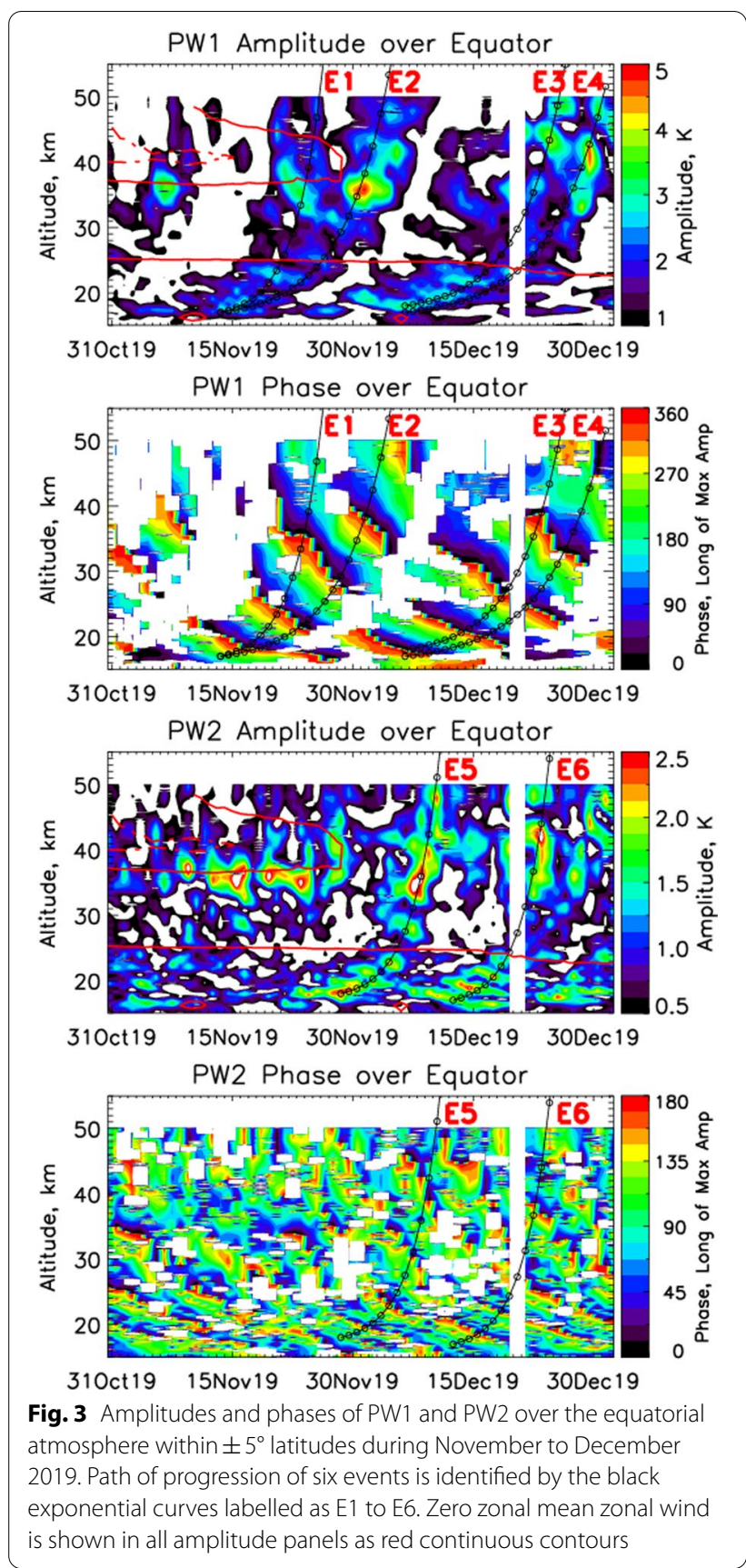

waves of two prominent periods can be seen to be separated and propagate upward as indicated by black exponential curves. These black exponential curves are drawn based on visual inspection only. The same curves are used in the phase plots to see the phase progression with time and altitude and to derive the vertical wavelength of the PW. The downward phase progression is indicative of the upward propagation of these waves. The first wave takes approximately 11 days to reach $\sim 40 \mathrm{~km}$ and the second wave takes $\sim 18$ days. These two waves are hereby identified as Events 1 and 2 labelled as E1 and E2 in the Figure. The wave in Event 1 dissipates at $\sim 36 \mathrm{~km}$ and its amplitude reduces significantly by the time it reaches $\sim 40 \mathrm{~km}$. Another feature is seen to originate on 6th December with two prominent waves dispersing into the higher altitudes as time progresses. The first wave takes 17 days to reach $\sim 40 \mathrm{~km}$ and the second wave takes 22 days. These waves are identified as Events 3 and 4 labelled as E3 and E4 in the Figure. Two more events are identified for PW2 starting on 28th November and 12th December, and are hereafter called Events 5 and 6 labelled as E5 and E6 in the Figure. Along with Event 6, another wave appears to disperse out to reach $40 \mathrm{~km}$ four days later. As its amplitude is much smaller, and the current exercise is based on visual inspection, it is not considered. Other smaller amplitude waves are also not considered. All events from 1 to 6 indicate that waves of different periods and same wavenumber are excited simultaneously, and depending upon the phase speeds, dispersion takes place and the waves separate out as they propagate upward. Further, these six events are also identified as eastward propagating and thereby as KW events from Fig. 1. Another notable feature in Fig. 3 is the oscillation in the wave amplitudes along the black curves just above the tropopause and could be due to superposition of the different waves of same wavenumber generated simultaneously. This feature is more prominent in PW2. As the different waves propagate upward and disperse, this oscillatory behaviour also disappears.

The six events identified above are investigated in greater detail in Fig. 4, which shows the amplitudes (top row) and phases giving longitude of maximum amplitude (bottom row) of the waves along the black exponential curves, i.e., along the path of progression of the events in Fig. 3. Sudden breaks are seen in the figure in amplitudes and phases as day number changes along curves (time of observation on a given day was neglected in the analysis which induces such sudden jumps). The amplitudes are in general increasing with altitude and oscillatory in nature, particularly in the lower altitudes, and peak at around $\sim 35 \mathrm{~km}$. The progression of phases, shown in the lower row of the figure, provides more information regarding the wave events. Vertical wavelength is calculated by fitting a line from -180 to $180^{\circ}$ longitude. For all waves in Events 1-6, the vertical wavelength is small near $20 \mathrm{~km}$ and increases as the wave propagates into higher altitudes. The vertical wavelength of PW1 events near tropopause is $\sim 3 \mathrm{~km}$ and increases to $10-12 \mathrm{~km}$ at $\sim 40 \mathrm{~km}$ altitude. This is proof of Doppler effect of mean zonal wind on the waves, where the westward zonal wind is increasing the vertical wavelength of the eastward propagating planetary waves. Further, the wavelength is 

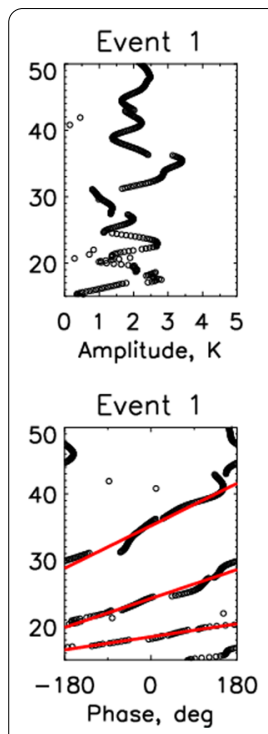
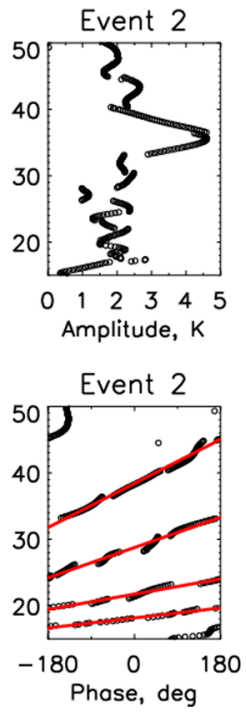

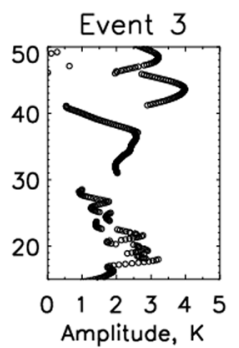

Event 3

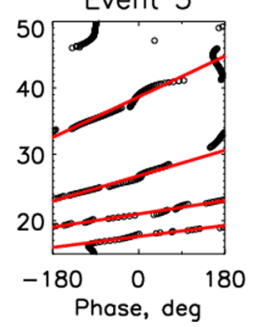

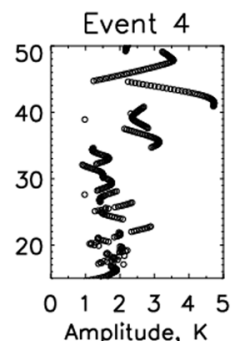
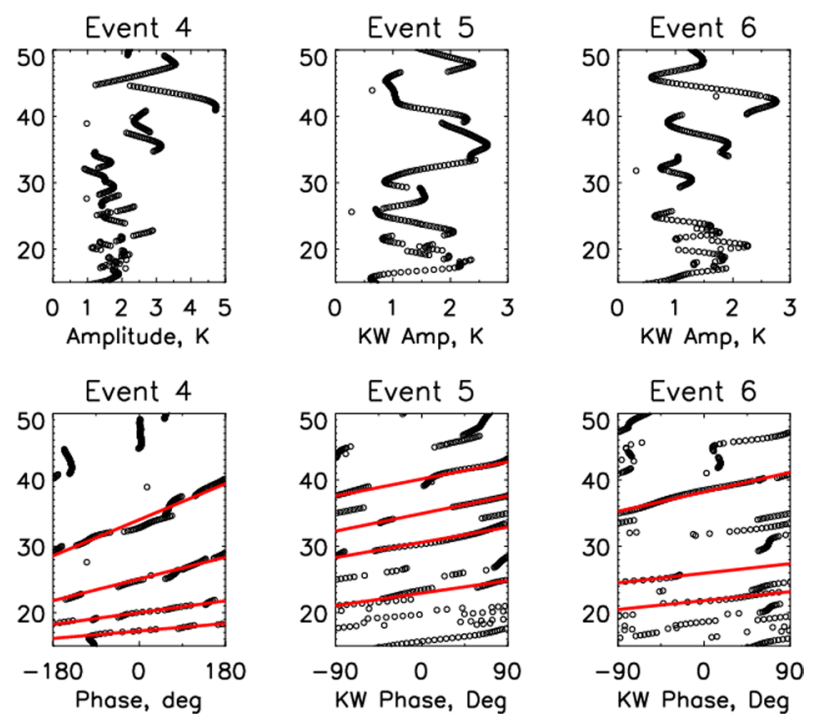

Fig. 4 Amplitudes (top row) and phases (bottom row) of the waves along the path of progression of Events 1 to 6 identified in Fig. 3

smaller for the wave that takes longer to reach the higher altitude (Event 2 and 4), indicating that the latter are slow waves. For Events 5 and 6, calculating the vertical wavelength was difficult as can be seen in the figure. It appears as though the events are a superposition of more than one wave that is distorting the phase profile and creating oscillatory behaviour in the amplitudes. Approximate vertical wavelengths are computed and found to be $6-7 \mathrm{~km}$ at $22 \mathrm{~km}$ and increase to $\sim 12 \mathrm{~km}$ as the waves near $40 \mathrm{~km}$.

COSMIC-2 temperatures are also analysed using a 2D-FFT to extract the eastward propagating KW in the spectral domain during a 64-day duration from 28th October to 31st December 2019. The spectral analysis is performed on the reconstructed temperature variability obtained from the fitted parameters of PW1 to PW6, where other smaller period variations, including tides, are discarded. The Fourier spectrum thus separates the observed amplitudes in Fig. 3 into eastward and westward propagating waves. The spectra for the above 64-day period at 36 and $18 \mathrm{~km}$ are shown in Fig. 5a, b. Both eastward and westward planetary waves of various periodicities can be observed and the spectra are dominated by wavenumbers 1 and 2. This also supports the earlier argument that the oscillatory nature in the amplitudes of PW1 and PW2 seen in Figs. 3 and 4, particularly in the lower altitudes near the tropopause region, could be due to superposition of many waves of the same wavenumber. Amplitudes and phases of eastward propagating KW of wavenumber 1 (KW1) and 2 (KW2) are extracted from these spectra at each altitude and shown in Fig. $5 \mathrm{c}-\mathrm{f}$ as a function of period and altitude. The spectra show significant slow and fast KW1 with periods of 21,16 , 11 , and 8 days and amplitudes ranging from 0.6 to $1 \mathrm{~K}$. The 21-day KW1 has an amplitude of $0.5 \mathrm{~K}$ in the lower stratosphere and shows two peaks of $0.9 \mathrm{~K}$ at $36 \mathrm{~km}$ and $0.8 \mathrm{~K}$ at $43 \mathrm{~km}$. The 16-day KW1 exhibits a maximum amplitude of $1.5 \mathrm{~K}$ at $20 \mathrm{~km}$ that gradually reduces with increasing altitude and again peaks at $36 \mathrm{~km}$ with $0.9 \mathrm{~K}$ amplitude. The amplitudes of the fast KW1 with periods of 11 and 8 days gradually increase to $1.2 \mathrm{~K}$ and $0.8 \mathrm{~K}$, respectively, peaking at $36 \mathrm{~km}$. Faster KW1 at 4.5- and 6.5-day periods are also seen but with very small amplitudes increasing from $\sim 0 \mathrm{~K}$ to $0.4 \mathrm{~K}$ at $50 \mathrm{~km}$. The associated phases at each of these periods (4.5-21 days) vary consistently and establish the presence of all these waves in the chosen 64-day duration. Amplitudes of KW2 in Fig. 5 are much smaller and almost negligible. The only noticeable feature is a 10.7-day wave with amplitudes of $0.4 \mathrm{~K}$ at $20 \mathrm{~km}$ decreasing to $0 \mathrm{~K}$ at $25 \mathrm{~km}$. Phase variation is also consistent only up to $25 \mathrm{~km}$. Slow and fast period wave variations of KW1 in real space are obtained separately by bandpass filtering followed by an inverse 2D-FFT. Figure 6 shows these bandpassed slow (1621 days) and fast (8-11 days) KW1 wave packets for the November to December 2019 period over the Equator and at $120^{\circ}$ longitude as a function of day number and altitude. Contours of temperature deviations of $1 \mathrm{~K}$ are shown by black continuous lines and those of $-1 \mathrm{~K}$ are shown by black dotted lines. Slow KW1 are a strong component that are excited around the tropopause in early November and propagate upward. Initially the waves appear to be convectively coupled and are confined to the lower stratosphere and vertical propagation begins only 

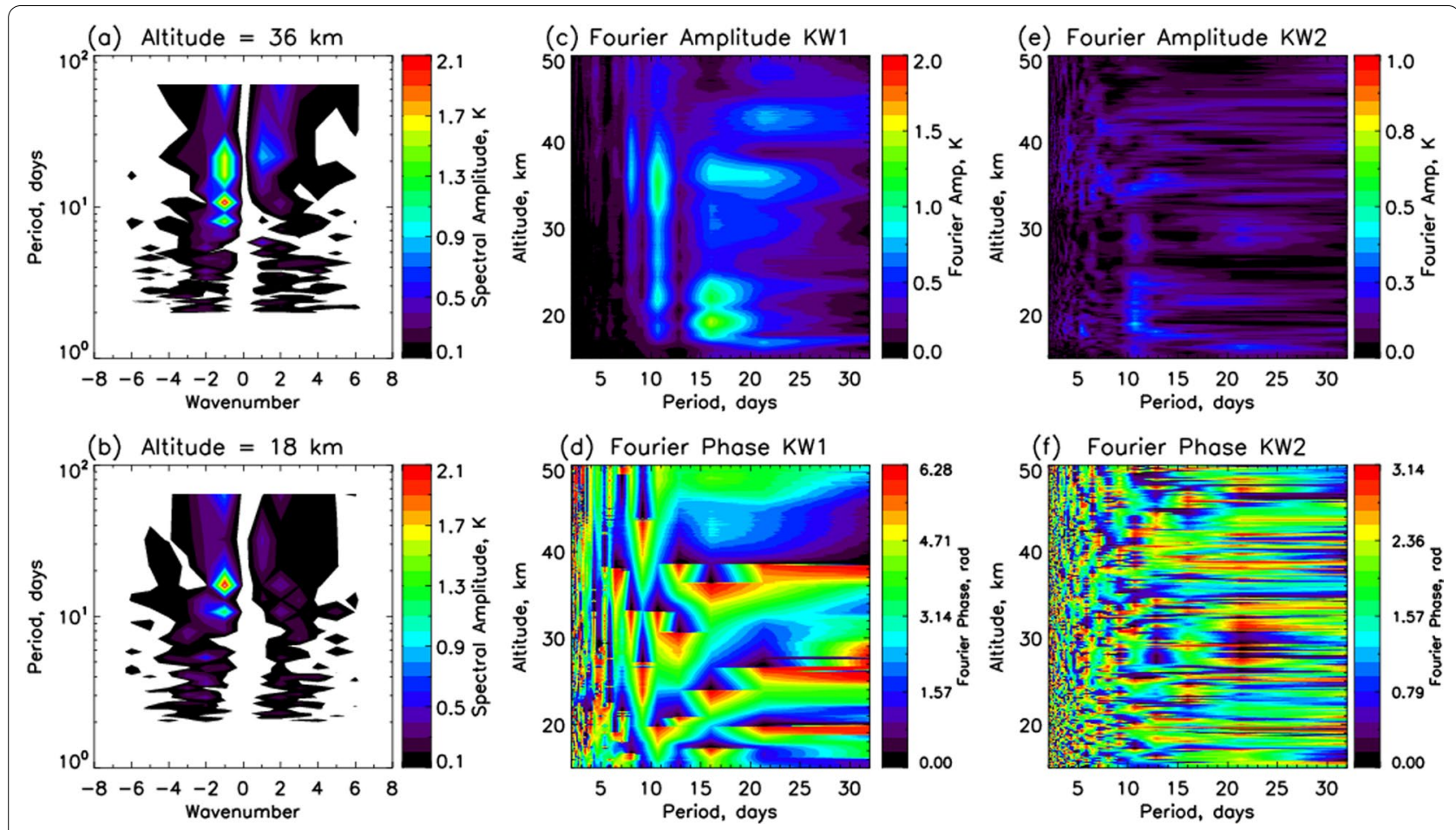

Fig. $\mathbf{5}$ a, $\mathbf{b}$ 2D-FFT spectrogam for the reconstructed temperatures at $36 \mathrm{~km}$ and $18 \mathrm{~km}$, $\mathbf{c}-\mathbf{f}$ Amplitudes and phases of KW1 and KW2 from two dimensional Fourier spectra as a function of period and altitude

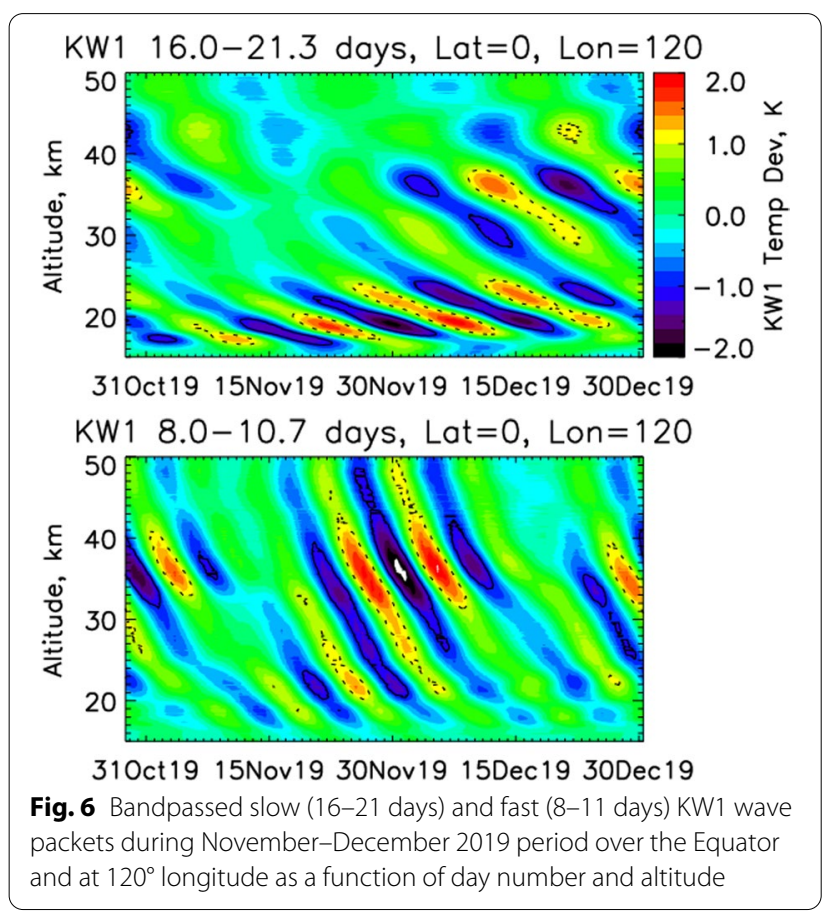

by late November. The waves soon reach $\sim 40 \mathrm{~km}$ altitude and continue to propagate. Similarly, the fast KW1 also appear to be generated at the same time in early November, albeit with small amplitudes, and propagate faster into the higher altitudes. This once again establishes that many waves are generated or excited simultaneously near the tropopause and the waves disperse with different speeds as they propagate upward in the form of wave packets. These features were not specifically seen earlier and the use of COSMIC-2 data provides the opportunity to look at the fine structure of the evolution of the KW of different periods.

Figure 7 shows the amplitudes and phases of KW1 of 4.5-, 6.5-, 8-, 10.7-, 16-, 21.3- day periods from Fourier analysis in the top and bottom rows, respectively. As already mentioned, 4.5- and 6.5-day waves have very small amplitudes and the fast waves (8- and 11-days) have larger amplitudes that increase with increasing altitude, consistent with waves propagating vertically upward into lower densities of the atmosphere. The slow waves on the other hand have large amplitudes in the lower altitudes that reduces with increasing altitude indicating dissipation of the wave along the path of propagation. The most interesting aspect are the phase variations where the vertical wavelengths are calculated. The 4.5-day wave has a very large wavelength of 

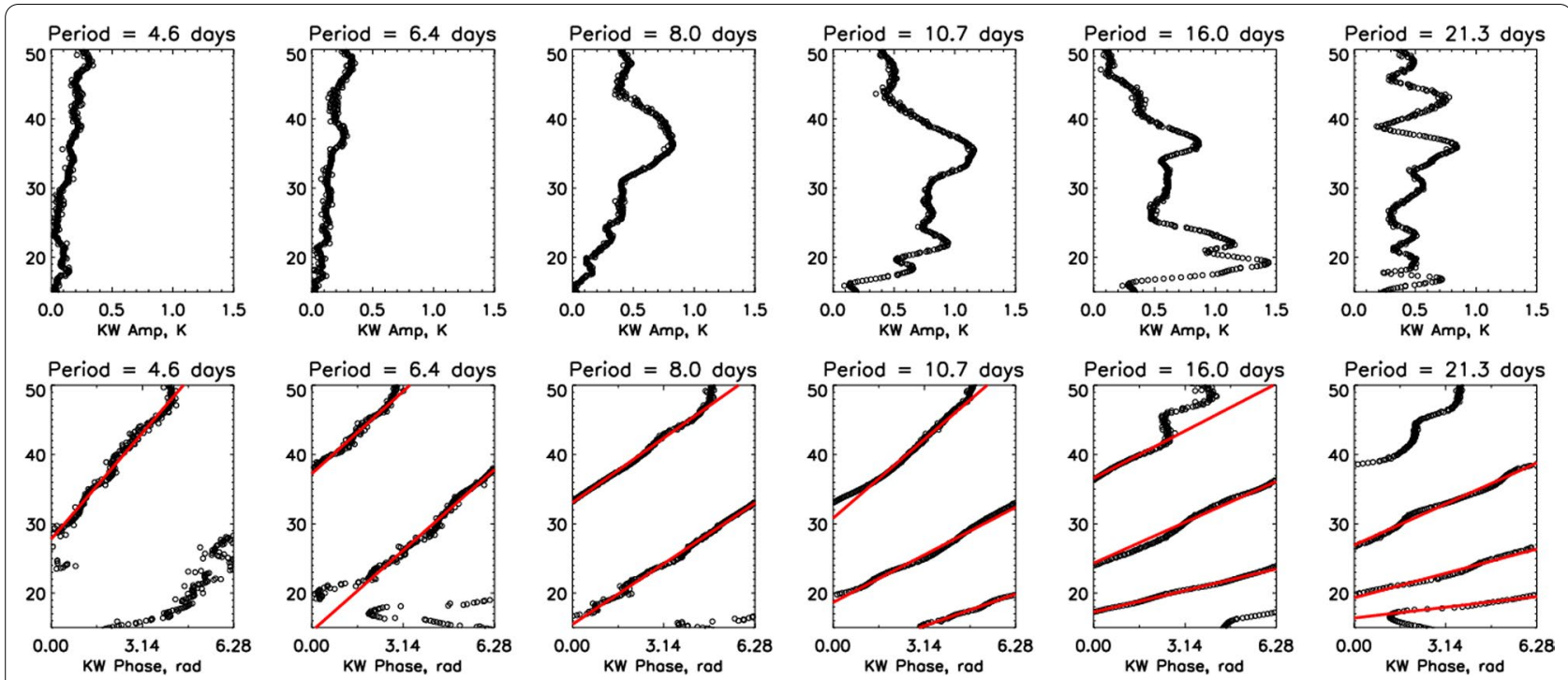

Fig. 7 Amplitudes (top row) and phases (bottom row) of KW1 of 4.5-, 6.5-, 8-, 11-, 16-, 21- day periods from two-dimensional Fourier analysis

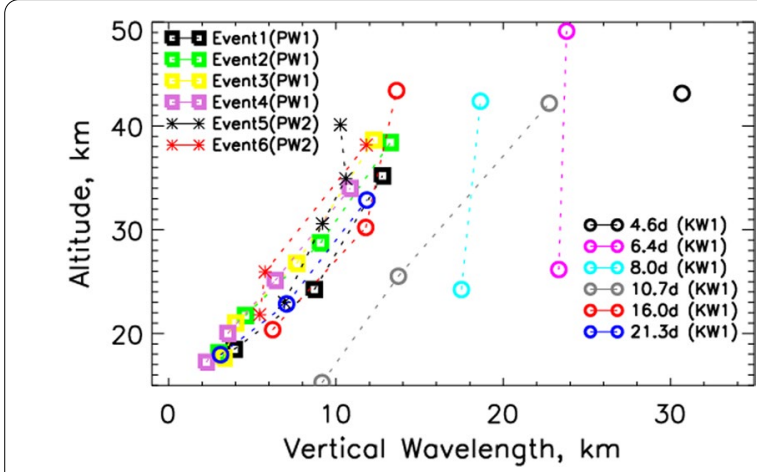

Fig. 8 Vertical wavelengths calculated for the individual waves in Fig. 4 and those calculated from the Fourier spectra in Fig. 7

$31 \mathrm{~km}$ encompassing the entire stratosphere and those of 6.5- and 8-day waves are 23 and $18 \mathrm{~km}$, respectively. These wavelengths remain constant and the waves do not appear to interact with the mean wind. 11-day wave wavelength changes from 9 to $23 \mathrm{~km}$, that of 16-day wave changes from 6 to $14 \mathrm{~km}$, and 21-day wave wavelength changes from 3 to $12 \mathrm{~km}$ from lower to upper stratosphere.

All vertical wavelengths calculated for the individual waves in Fig. 4 and those calculated from the Fourier spectra in Fig. 7 are shown in Fig. 8. The individual wave events (investigated by visual inspection) are the longer period waves and the vertical wavelengths match the ones obtained from the Fourier spectrum very well. Further, the wavelength increases with altitude due to the Doppler effect of the mean westward zonal wind on the waves. In spite of increased wavelengths, the waves dissipate at $36-40 \mathrm{~km}$ as the mean westward wind reduces and the reverse could possibly happen. Also, as seen in Fig. 1, when the waves encounter the zero wind lines, or the wind shears, the slow KW dissipate. Importantly, COSMIC-2 refractivity profiles from which temperature profiles are deduced are reliable up to $40-45 \mathrm{~km}$ (Schreiner et al. 2020) and hence it is difficult to conclude these aspects beyond $40 \mathrm{~km}$. The increase in vertical wavelength with increasing altitude is absent for the fast waves, whose values are very large and propagate vertically upward indicating little wavemean flow interaction. Thus, these waves are capable of reaching the MLT region (Forbes et al. 2009).

The 2D-FFT is applied at other times also (not shown here) and it is observed that during July-August 2020, when PW1 was observed up to $25 \mathrm{~km}$ in Fig. $2 \mathrm{a}$, the periods of dominant KW1 are found to be 13 and 16 days and the vertical wavelengths are found to be $13 \mathrm{~km}$ and $9 \mathrm{~km}$, respectively. It can also be seen in Fig. 2a that only one wave manages to cross the westerly regime. It is observed from bandpassed reconstructions that the 13-day wave with larger vertical wavelength is the one that propagates to upper stratosphere by mid-August while the slow 16-day wave with smaller wavelength gets dissipated at the wind shear at $25 \mathrm{~km}$. KW2 are also observed during this two-month duration with periods of 13 and 21 days, but their vertical wavelengths are very small and range from 3 to $4 \mathrm{~km}$ and thereby are dissipated at the wind shear at $25 \mathrm{~km}$. Similar observations are made at other durations also clearly establishing the effect of mean wind on the KW generated at the tropopause. 
These observations from the current study clearly indicate that many waves are generated simultaneously near the tropopause and each component propagates upward with a different phase speed, resulting in dispersion. Davis et al (2012) extracted vertical wavelengths from the phase information of the waves and found average vertical wavelength to be $44 \pm 2 \mathrm{~km}$ for UFKW of periods $2.5-$ 4.5 days in the MLT region. This looks to be reasonably agreeing with the $31 \mathrm{~km}$ wavelength extracted at $\sim 40 \mathrm{~km}$ altitude in the current study for only the 4.5-day KW1. Evidently, smaller period waves would have much longer wavelengths justifying the agreement. Theoretical estimations were also done by Davis et al (2012) and were found to match with their observations.

In the current study, a theoretical estimation of vertical wavelength, $\mathrm{L}_{\mathrm{z}}$, for slow and fast waves in the lower stratosphere is performed using Eq. (1). For the 21-day KW1 the theoretical vertical wavelength is $\sim 6 \mathrm{~km}$ at $25 \mathrm{~km}$ altitude where $\bar{u}=\sim 0 \mathrm{~m} / \mathrm{s}$ (assuming $\mathrm{N}^{2}=5 \times 10^{-4} \mathrm{~s}^{-2}$ for stratosphere). Similarly for a 16-day wave it is $\sim 8 \mathrm{~km}$, for a 11-day wave it is $\sim 12 \mathrm{~km}$ and for an 8 -day KW1 it is $16 \mathrm{~km}$. These values are in good agreement with the observed values in Fig. 8. Forbes et al (2009) calculated the vertical wavelengths theoretically using Eq. (1) and found it to be $14 \mathrm{~km}$ for 9-day KW1 at $40 \mathrm{~km}$. According to the current study this is a lower estimate.

\section{Summary and conclusions}

FORMOSAT-7/COSMIC-2 temperatures in the stratosphere are analysed to investigate the equatorial atmospheric KW during September 2019-March 2021, with special emphasis during November-December 2019. COSMIC-2 data is of high vertical resolution and provide approximately $4000-5000$ profiles per day. These measurements provide a unique opportunity for investigating the fine structure of the wave dynamics in the stratosphere. In this study, KW characteristics are derived from COSMIC-2 temperatures over the equatorial region $\left( \pm 5^{\circ}\right)$. Mean flow interactions are investigated both from long term wave activity as well as by identifying individual KWs in conjunction with ERA5 reanalysis zonal wind data. The important results obtained in the study are as follows:

1. Planetary scale waves of wavenumber 1 are identified to be mostly $\mathrm{KW}$ in the equatorial stratosphere. They are the strongest component of variability with total amplitudes reaching $4 \mathrm{~K}$ at 35 to $40 \mathrm{~km}$. The amplitudes of the individual KW1 waves of periods from 8 to 21 days vary between 0.8 and $1.5 \mathrm{~K}$. Waves of wavenumber 2 also have high amplitudes reaching $2.5 \mathrm{~K}$, however, the KW2 component amplitudes are smaller as seen in the Fourier analysis and less than $0.5 \mathrm{~K}$.

2. La Nina event of 2020/21 suppressed the KW activity during the second half of the study period, i.e., after July 2020.

3. Wave-mean flow interactions are clearly observed in the variability of PW1 and PW2, with amplitudes suddenly reducing as zero wind contours are encountered. In this study, the fine structure of these waves is investigated for individual events along the path of wave propagation from the tropopause to higher altitudes.

4. Independent $\mathrm{KW}$ events are identified and analyzed to show that group of waves of different periods are generated simultaneously and disperse into the upper atmosphere as they propagate eastward and vertically upward with different phase speeds.

5. The periods of these dispersing KW are 11 days and larger while the vertical wavelengths are $3 \mathrm{~km}$ at the tropopause and increase gradually to $10-12 \mathrm{~km}$ at $\sim 40 \mathrm{~km}$. This clearly indicates wave-mean flow interactions and the doppler effect of the ambient westward wind (during November-December 2019) on the increasing vertical wavelength of the slow waves. Fast waves of 4.5-8 days are also identified in the Fourier analysis. The vertical wavelengths of the waves with periods $8,6.5$ and 4.5 days are 18,24 and $30 \mathrm{~km}$, respectively. These wavelengths are large and approximately constant throughout the stratosphere, indicating no interaction of the wave with the mean flow, thereby enabling them to reach higher altitudes. It would be very interesting to track such events into the MLT region. Theoretical estimates of these vertical wavelengths also agree very well with these observations.

Long term variations of $\mathrm{KW}$ and their effect on $\mathrm{QBO}$ are fairly understood. However, questions still remain regarding their generation and subsequent propagation/ dispersion. The correlation with convective activity is not good at all times, particularly if individual wave to source connections are to be identified. Further research is required in this direction to understand the nature of KW generation which might answer the intermittency in the wave amplitudes near the tropopause. This is also important in investigations of the upper atmosphere, particularly the study of short-term variability of the IT system, where UFKW are known to have a significant impact.

COSMIC-2 is providing unprecedented data both in terms of quantity and quality thereby opening new doors to investigate atmospheric processes in greater detail than ever done before. The current study is a step 
in this direction and poses many questions that need to be answered regarding middle atmospheric dynamics. How are the various waves and tides generated? How can we relate them to the deep convections in the lower atmosphere? What are the effects of ENSO on the waves and wave-mean flow interactions? What physical processes are responsible for these effects? In future, other planetary waves along with KW will be investigated using COSMIC-2 data to obtain a complete picture of the global stratosphere. These studies will considerably improve the current understanding of the global middle atmosphere.

\begin{abstract}
Acknowledgements
Authors thank UCAR/CDAC for free access to COSMIC-2 data from their website at https://www.cosmic.ucar.edu/. ERA5 zonal wind data is obtained from https://cds.climate.copernicus.eu/cdsapp\#!/home. Interpolated OLR data is provided by NOAA/OAR/ESRL PSL, Boulder, Colorado, USA, from their Web site at https://psl.noaa.gov/data/gridded/data.interp_OLR.html. ChenJeih Pan and Shih-Sian Yang are supported by the Ministry of Science and Technology of Taiwan through the Grants MOST-109-2811-M-008-542 and MOST-109-2111-M-008-003.
\end{abstract}

\section{Authors' contributions}

UD-Conceptualisation, methodology, analysis, original draft preparation, writing and editing. C-JP-Conceptualisation, investigations, writing and editing. S-SY - methodology, analysis, original draft preparation, writing and editing. All authors read and approved the final manuscript.

\section{Funding}

Chen-Jeih Pan and Shih-Sian Yang are supported by the Ministry of Science and Technology of Taiwan through the grants MOST-109-2811-M-008-542 and MOST-109-2111-M-008-003.

\section{Availability of data and materials}

All data used in the current study is freely available. Authors thank UCAR/ CDAC for free access to COSMIC-2 data from their website at https://www. cosmic.ucar.edu/. ERA5 zonal wind data is obtained from https://cds.climate. copernicus.eu/cdsapp\#!/home. Interpolated OLR data is provided by NOAA/ OAR/ESRL PSL, Boulder, Colorado, USA, from their Web site at https://psl.noaa. gov/data/gridded/data.interp_OLR.html.

\section{Declarations}

\section{Competing interests}

The authors declare no competing interests.

\section{Author details}

'Indian Institute of Information Technology Kalyani, Kalyani 741235, West Bengal, India. ${ }^{2}$ Department of Space Science and Engineering, National Central University, Jhongli, Taoyuan 32001, Taiwan.

Received: 27 January 2022 Accepted: 13 February 2022

Published online: 22 February 2022

\section{References}

Baldwin MP, Gray LJ, Dunkerton TJ, Hamilton K, Haynes PH, Randel WJ, Holton JR, Alexander MJ, Hirota I, Horinouchi T, Jones DBA, Kinnersley JS, Marquardt C, Sato K, Takahashi M (2001) The Quasi-Biennial oscillation. Rev Geophys 39(2):179-229. https://doi.org/10.1029/1999RG000073

Canziani PO, Holton JR (1998) Kelvin Waves and the quasi-biennial oscillation: an observational Analysis. J Geophys Res 103:31509-31521. https://doi. org/10.1029/1998JD200021
Canziani PO, Holton JR, Fishben E, Froidevaux L, Waters JW (1994) Equatorial Kelvin Waves: a UARS MLS View. J Atmos Sci 51:3053-3076

Chang LC, Palo SE, Liu H-L, Fang T-W, Lin CS (2010) Response of the thermosphere and ionosphere to an ultra fast Kelvin wave. J Geophys Res 115:A00G04. https://doi.org/10.1029/2010JA015453

Chen Y-W, Miyahara S (2012) Analysis of fast and ultrafast Kelvin waves simulated by the Kyushu-GCM. J Atmos Sol Terr Phys 80:1-11. https://doi.org/ 10.1016/j.jastp.2012.02.026

Chen W-S, Pan CJ, Das U (2018) The mean zonal wind effect on the long-term variation of ultra-fast Kelvin waves in the mesosphere and lower thermosphere and in the upper stratosphere. J Atmos Sol Terr Phys 179:459-467. https://doi.org/10.1016/j.jastp.2018.10.006

Copernicus Climate Change Service (C3S) (2017) ERA5: Fifth generation of ECMWF atmospheric reanalyses of the global climate. Copernicus Climate Change Service Climate Data Store (CDS), Date of Access 26 May 2021. Retrieved from https://cds.climate.copernicus.eu/cdsapp\#!/home

Das U, Pan CJ (2013) Strong Kelvin wave activity observed during the westerly phase of QBO-A case study. Ann Geophys 31:581-590. https://doi.org/ 10.5194/angeo-31-581-2013

Das U, Pan CJ (2016) Equatorial atmospheric Kelvin waves during El Niño episodes and their effect on stratospheric QBO. Sci Total Environ 544:908918. https://doi.org/10.1016/j.scitotenv.2015.12.009

Davis RN, Chen Y-W, Miyahara S, Mitchell NJ (2012) The climatology, propagation and excitation of ultra-fast Kelvin waves as observed by meteor radar, Aura MLS, TRMM and in the Kyushu-GCM. Atmos Chem Phys 12:1865-1879. https://doi.org/10.5194/acp-12-1865-2012

Dee DP et al (2011) The ERA-Interim reanalysis: configuration and performance of the data assimilation system. Q J Roy Meteorol Soc 137:553-597. https://doi.org/10.1002/qj.828

Domeisen DI, Garfinkel Cl, Butler AH (2019) The teleconnection of El Niño Southern Oscillation to the stratosphere. Rev Geophys 57:5-47. https:// doi.org/10.1029/2018RG000596

Drob DP, Emmert JT, Meriwether JW, Makela JJ, Doornbos E, Conde M, Hernandez G, Noto J, Zawdie KA, McDonald SE, Huba JD, Klenzing JH (2015) An update to the Horizontal Wind Model (HWM): the quiet time thermosphere. Earth Space Sci 2:301-319. https://doi.org/10.1002/2014E A000089

Ern M, Preusse P (2009a) Quantification of the contribution of equatorial Kelvin waves to the QBO wind reversal in the stratosphere. Geophys Res Lett 36:L21801. https://doi.org/10.1029/2009GL040493

Ern M, Preusse P (2009b) Wave fluxes of equatorial Kelvin waves and QBO zonal wind forcing derived from SABER and ECMWF temperature spacetime spectra. Atmos Chem Phys 9:3957-3986. https://doi.org/10.5194/ acp-9-3957-2009

Forbes JM (2000) Wave coupling between the lower and upper atmosphere: case study of an ultra-fast Kelvin Wave. J Atmos Sol Terr Phys 62:16031621. https://doi.org/10.1016/S1364-6826(00)00115-2

Forbes JM, Zhang X, Palo SE, Russell J, Mertens CJ, Mlynczak MG (2009) Kelvin waves in stratosphere, mesosphere and lower thermosphere temperatures as observed by TIMED/SABER during 2002-2006. Earth, Planets Space 61:447-453. https://doi.org/10.1186/BF03353161

Hersbach H, Bell B, Berrisford P, Biavati G, Horányi A, Muñoz Sabater J, Nicolas J, Peubey C, Radu R, Rozum I, Schepers D, Simmons A, Soci C, Dee D, Thépaut J-N (2018) ERA5 hourly data on pressure levels from 1979 to present. Copernicus Climate Change Service (C3S) Climate Data Store (CDS). ERA5 hourly data on pressure levels from 1979 to present. Copernicus Climate Change Service (C3S) Climate Data Store (CDS). https://doi.org/10.24381/ cds.bd0915c6

Hirota I (1979) Kelvin waves in the equatorial middle atmosphere observed by the Nimbus 5 SCR. J Atmos Sci 36:217-222

Ho S-P, Anthes RA, Ao CO, Healy S, Horanyi A, Hunt D, Mannucci AJ, Pedatella N, Randel WJ, Simmons A, Steiner A, Xie F, Yue X, Zeng Z (2020) The COSMIC/FORMOSAT-3 radio occultation mission after 12 years: accomplishments, remaining challenges, and potential impacts of COSMIC-2. Bull Am Meteor Soc 101:E1107-E1136. https://doi.org/10.1175/ BAMS-D-18-0290.1

Holton JR, Lindzen RD (1968) A note on 'Kelvin' waves in the atmosphere. Mon Wea Rev 96:385-386. https://doi.org/10.1175/1520-0493(1968)096\% 3c0385:ANOKWI\%3e2.0.CO;2

Holton JR, Alexander MJ, Boehm MT (2001) Evidence for short vertical wavelength Kelvin waves in the Department of Energy-Atmospheric Radiation 
Measurement Nauru99 radiosonde data. J Geophys Res 106:2012520129. https://doi.org/10.1029/2001JD900108

Hovmöller E (1949) The Trough-and-Ridge diagram. Tellus 1:62-66. https://doi. org/10.1111/j.2153-3490.1949.tb01260.x

Kumar KN, Sharma SK, Joshi V, Ramkumar TK (2019) Middle atmospheric planetary waves in contrasting QBO phases over the Indian low latitude region. J Atmos Solar Terr Phys 193:105068. https://doi.org/10.1016/j. jastp.2019.105068

Liebmann B, Smith CA (1996) Description of a complete (Interpolated) outgoing longwave radiation dataset. Bull Amer Meteor Soc 77:1275-1277

Lindzen RD, Holton JR (1968) A theory of the Quasi-Biennial oscillation. J Atmos Sci 25:1095-1107. https://doi.org/10.1175/1520-0469(1968)025\% 3c1095:ATOTQB\%3e2.0.CO;2

Lott F, Denvil S, Butchart N, Cagnazzo C, Giorgetta MA, Hardiman SC, Manzini E, Krismer T, Duvel J-P, Maury P, Scinocca JF, Watanabe S, Yukimoto S (2014) Kelvin and Rossby-gravity wave packets in the lower stratosphere of some high-top CMIP5 models. J Geophys Res Atmos 119:2156-2173. https://doi.org/10.1002/2013JD020797

Matsuno T (1966) Quasi-geostrophic motions in the equatorial area. J Met Soc Japan 44:25-43. https://doi.org/10.2151/jmsj1965.44.1_25

Mote PW, Dunkerton TJ, Wu D (2002) Kelvin waves in stratospheric temperature observed by the Microwave Limb Sounder. J Geophys Res 107(D14):4218. https://doi.org/10.1029/2001JD001056

Pan CJ, Das U, Yang SS, Wong CJ, Lai HC (2011) Investigation of Kelvin waves in the stratosphere using FORMOSAT-3/COSMIC temperature data. J Met Soc Japan 89A:83-96. https://doi.org/10.2151/jmsj.2011-A05

Pan C-J, Yang S-S, Das U, Chen W-S (2020) Morphology of the wavenumber 1 and wavenumber 2 stratospheric Kelvin waves using the long-term erainterim reanalysis dataset. Atmosphere 11:421. https://doi.org/10.3390/ atmos 11040421

Poli P, Healy SB, Dee DP (2010) Assimilation of Global Positioning System radio occultation data in the ECMWF ERA? Interim reanalysis. Q I R Meteorol Soc 136:1972-1990. https://doi.org/10.1002/aj.722

Randel WJ, Wu F (2005) Kelvin wave variability near the equatorial tropopause observed in GPS radio occultation measurements. J Geophys Res 110:D03102. https://doi.org/10.1029/2004JD005006

Ratnam MV, Tsuda T, Kozu T, Mori S (2006) Long-term behavior of the Kelvin waves revealed by CHAMP/GPS RO measurements and their effects on the tropopause structure. Ann Geophys 24:1355-1366. https://doi.org/10. 5194/angeo-24-1355-2006

Salby ML, Hartmann DL, Bailey PL, Gille JC (1984) Evidence for equatorial Kelvin waves in nimbus-7 LIMS. J Atmos Sci 41:220-235. https://doi.org/10. 1175/1520-0469(1984)041\%3c0220:EFEKMI\%3e2.0.CO;2

Scherllin-Pirscher B, Randel WJ, Kim J (2017) Tropical temperature variability and Kelvin-wave activity in the UTLS from GPS RO measurements. Atmos Chem Phys 17:793-806. https://doi.org/10.5194/acp-17-793-2017

Schreiner WS, Weiss JP, Anthes RA, Braun J, Chu V, Fong J, Hunt D, Kuo Y-H, Meehan T, Serafino W, Sjoberg J, Sokolovskiy S, Talaat E, Wee TK, Zeng Z (2020) COSMIC-2 radio occultation constellation: first results. Geophys Res Lett. https://doi.org/10.1029/2019GL086841

Sridharan S, Tsuda T, Nakamura T, Kozu T, Mori S, Russell JM (2006) Observations of the 7-day Kelvin wave in the tropical atmosphere during the CPEA campaign. J Meteorol Soc Jpn 84A:259-275. https://doi.org/10. 2151/jmsj.84A.259

Takahashi H, Wrasse CM, Fechine J, Pancheva D, Abdu MA, Batista IS, Lima LM, Batista PP, Clemesha BR, Schuch NJ, Shiokawa K, Gobbi D, Mlynczak MG, Russell JM (2007) Signatures of ultra fast Kelvin waves in the equatorial middle atmosphere and ionosphere. Geophys Res Lett 34:L11108. https://doi.org/10.1029/2007GL029612

Triplett CC, Immel TJ, Wu Y-J, Cullens C (2019) Variations in the ionospherethermosphere system from tides, ultra-fast Kelvin waves, and their interactions. Adv Space Res 64:1841-1853. https://doi.org/10.1016/j.asr. 2019.08.015

Tsai H-F, Tsuda T, Hajj GA, Wickert J, Aoyama Y (2004) Equatorial Kelvin waves observed with GPS occultation measurements (CHAMP and SAC-C). J Meteorol Soc Jpn 82:397-406. https://doi.org/10.2151/jmsj.2004.397

Tsuda T, Ratnam MV, Kozu T, Mori S (2006) Characteristics of 10-day Kelvin Wave Observed with Radiosondes and CHAMP/GPS Occultation during the CPEA Campaign (April-May, 2004). J Meteorol Soc Jpn 84A:277-293. https://doi.org/10.2151/jmsj.84A.277
UCAR COSMIC Program (2019) COSMIC-2 Data Products (WetPf2). UCAR/ NCAR—COSMIC, Access date: 22 May 2021. https://doi.org/10.5065/ T353-C093

Voosen P (2021) Global temperatures in 2020 tied record highs. Science 371:334-335. https://doi.org/10.1126/science.371.6527.334

Wallace JM, Kousky VE (1968) Observational evidence of Kelvin waves in the tropical stratosphere. J Atmos Sci 25:900-907

Yamazaki Y, Miyoshi Y, Xiong C, Stolle C, Soares G, Yoshikawa A (2020) Whole atmosphere model simulations of ultrafast Kelvin wave effects in the ionosphere and thermosphere. J Geophys Res Space Phys. https://doi. org/10.1029/2020JA027939

Yang G, Hoskins B (2013) ENSO impact on Kelvin waves and associated tropical convection. J Atmos Sci 70:3513-3532. https://doi.org/10.1175/ JAS-D-13-081.1

\section{Publisher's Note}

Springer Nature remains neutral with regard to jurisdictional claims in published maps and institutional affiliations.

\section{Submit your manuscript to a SpringerOpen ${ }^{\circ}$ journal and benefit from:}

- Convenient online submission

- Rigorous peer review

- Open access: articles freely available online

- High visibility within the field

- Retaining the copyright to your article

Submit your next manuscript at $\boldsymbol{\nabla}$ springeropen.com 